\title{
A Survey on the use of Social BPM in Practice in Brazilian Organizations
}

\author{
Matheus Froes Batista \\ Andréa Magalhães Magdaleno \\ Marcos Kalinowski \\ UFF - Fluminense Federal University \\ UFF - Fluminense Federal University \\ IC - Computing Institute \\ UFF - Fluminense Federal University \\ IC - Computing Institute \\ Zip 24210-346 - Niterói - RJ - Brazil \\ IC - Computing Institute \\ Zip 24210-346 - Niterói - RJ - Brazil Z \\ matheusfb@id.uff.br \\ dheka - Consultoria em TI \& Gestão \\ www.dheka.com.br \\ andrea@ic.uff.br
}

\begin{abstract}
Social BPM is the combination of Business Process Management (BPM) with social and collaborative techniques for the purpose of exploring collaboration among stakeholders throughout the BPM lifecycle. Its goals are to reduce common problems in BPM by ensuring collaboration and transparency. To the best of our knowledge, there is no information on how Social BPM is being used in organizational environments and on its impacts. This study aims at showing how Brazilian organizations are using Social BPM practices and technologies. Therefore, a survey was conducted with employees from different companies in order to collect data on their usage of BPM collaborative practices. The survey received 31 replies and 3 of the respondents were also interviewed in order to provide depth to their answers and to enhance the overall understanding. The results show that collaboration happens predominantly in design, modeling, and improvement phases. Collaboration still happens mainly without formal planning and without tool support.
\end{abstract}

\section{CCS Concepts}

- Human-centered computing $\rightarrow$ Empirical studies in collaborative and social computing Applied computing $\rightarrow$ Business process management

\section{General Terms}

Management.

\section{Keywords}

Social BPM; Collaboration; Business Process Management; BPM; Survey.

\section{INTRODUCTION}

Social technology is already present in society's daily life. Users exchange instant messages, interact through social networks or use blogs, forums, and wikis to share and to receive information on any topic of interest. Tapscott [1] cited four principles required for dealing with the current open world: collaboration, transparency, sharing, and empowerment among customers and employees.

Businesses and organizations will remain competitive mainly if they manage their processes in this new, connected, and open

Permission to make digital or hard copies of all or part of this work for personal or classroom use is granted without fee provided that copies are not made or distributed for profit or commercial advantage and that copies bear this notice and the full citation on the first page. To copy otherwise, or republish, to post on servers or to redistribute to lists, requires prior specific permission and/or a fee.

SBSI 2017, June $5^{\text {th }}-8^{\text {th }}, 2017$, Lavras, Minas Gerais, Brazil.

Copyright SBC 2017. scenario. The internal environment of today's organizations will need to follow the capacity of interaction and collaboration of their professionals through technology, in order to guarantee the execution of their business processes with tasks that are more complex, less bureaucratic, that require more autonomy, and that are connected to the external environment [3].

In these dynamic work environments, traditional BPM approaches, which typically have focused on highly repetitive and structured processes, often encountered difficulties. Thereat, BPM began to evolve to this new open world and to support collaboration through the use of social technologies and features. This phenomenon is currently known as Social BPM [17, 19].

Social BPM consists of the fusion of social and collaborative practices and technologies with business process management in order to involve all relevant stakeholders in the BPM lifecycle $[17,19]$. Literature suggests that Social BPM can reduce or avoid some classic BPM problems, such as differences between process modeling and process execution or omission of ideas to process innovation or improvement, since it promotes a more collaborative and transparent environment [10].

Social BPM also has the potential to bridge the gap to collaboration, innovation, and co-participation. Thus, BPM research and market tools have evolved and developed products and practices to support Social BPM in organizational BPM initiatives.

However, to the best of our knowledge, there is no information regarding the actual use of Social BPM in organizations in practice and how it affects the involved stakeholders. Surveys on BPM were previously performed on organizations, including one survey on Brazilian organizations [2]. Nevertheless, these surveys did not focus on any aspects of collaboration or participation during BPM phases. This emphasizes the need for an experimental study regarding this topic. The absence of this information can be discouraging if one wants to apply Social BPM practices in an organization, because the actual advantages and disadvantages are still unknown.

For this reason, interest sprouts in investigating if organizations are actually using Social BPM and how this usage is happening. In this context, it would be useful to know what software tools are being used, what challenges are faced and how they are overcome, what results are expected, and what results are actually achieved. Another interesting aspect concerns the knowledge on how organizations use Social BPM in each of the BPM lifecycle phases.

The main goal of this paper is to provide an overview regarding Social BPM use in Brazilian organizations. In order to achieve this goal, a survey was conducted with organizations' members to understand their BPM practices and to know if and how social 
practices are being used. After the execution and an initial analysis, three subjects were selected for individual interviews in order to develop and enhance their initial answers. Results indicate that collaboration still happens without formal planning and tool support and that it happens predominantly in the BPM design, modeling, and improvement lifecycle phases.

The remainder of this paper is structured as follows. Section 2 defines collaboration, social software, BPM and Social BPM as the background topics of this work. Section 3 presents the research planning. Section 4 discusses the results achieved by the survey and interviews and potential threats to validity. Finally, conclusions and further work are summarized in Section 5.

\section{BACKGROUND}

\subsection{Collaboration and Social Software}

The word collaboration derives from latin words com and laborare - meaning labor together. In this research, collaboration is understood as defined by de Vreede and Briggs (2005) [5] as "making a joint effort towards a goal". By collaborating, people combine their expertise, insights, and resources in order to perform a group activity, accomplishing more than they could as separate individuals [6].

The reasons why a particular group of people come together to perform a given task can be as varied as possible. When a task or problem is large, complex or requires multiple skills, it is necessary to join the efforts of several people. In general, groups are formed to construct a product that can be as concrete as text, software, or the design of an artifact; or as abstract as a decision or the formation of a common knowledge on a certain subject.

Collaboration support through software (or groupware) has been a research topic for some time now [5,9]. Social media, mobile computing and cloud storage have been merging lately and turning collaboration in an actual user need. Not only users have been using social software for personal needs, but organizations have been adopting it too $[3,11]$.

Social software is defined as "software that supports the interaction of human beings and production of artifacts by combining the input from independent contributors without predetermining the way how to do this". This means it allows communication between two independent people (who may or may not know each other) and the creation of collaboration artifacts [18]. Some examples of social software include: social networks (Facebook, LinkedIn, Twitter), wiki (Wikipedia, wikiHow), social bookmarking (Pinterest), blogs (Blogger, Tumblr, WordPress).

\subsection{Business Process Management (BPM)}

Business processes can be understood as "a collection of events, activities and decisions that collectively lead to an outcome that brings value to an organization's customers" [8]. Business processes can reflect different domains, such as oil and gas, insurance, or even software development.

Business Process Management (BPM) consists of concepts, methods and techniques for defining, controlling and transforming an organization's business processes. Some common goals include cost reduction, execution time reduction and quality improvement, while ensuring client satisfaction [8].

BPM can be understood as a continuous cycle composed by the following phases: design, modeling, simulation, execution, monitoring, and improvement. Design consists of defining BPM goals, scope, and essential elements. Modeling consists of representing the process as a graphical model, using a previously defined notation. Simulation is for validating the model, ensuring that performance and results come as expected. Execution consists of implementing the modeled process in the organization. Monitoring is for analyzing performance indicators and evaluating processes' execution. Finally, Improvement consists of evaluating the current situation of business processes and identifying potential improvements [1].

During BPM use, two main problems may occur: model-reality division and lost innovation [10]. Model-reality division happens when a process is modeled and deployed in a way, but it is executed in another one. Lost innovation happens when a process stakeholder has knowledge on how to improve the process, but this knowledge is never applied or shared, because the guidelines for changes are not clear or because s/he feels success is unlikely $[10,17]$. One reason for these problems is the adoption of a topdown BPM approach, which means that the group of people conducting the BPM activities does not necessarily include the main process executors or stakeholders [10].

\subsection{Social BPM}

Social BPM aims to address the problems previously mentioned and to promote collaboration between stakeholders [18]. Even though there is no consensus among authors, in this research, Social BPM is defined as the combination of social software and BPM to achieve a more participative BPM. Its goals include connecting processes and people in order to ensure collaboration, transparency, and participation $[10,19,20]$.

Social BPM can happen during each phase of the BPM lifecycle with or without the aid of software. Each BPM phase has room for collaboration techniques and some of them are already present in BPMS (BPM Software). For example, process design and modeling usually happens with process experts, however it can be improved with the contribution of diverse stakeholders (even if they don't know process modeling notations); knowledge sharing can be explicitly used throughout all phases; process execution can be more adaptive and allow better involvement between internal and external users; also in execution, processes can become more dynamic and then improve their visibility for stakeholders; process monitoring can be improved with real-time notifications for the users; process improvements ideas can be shared through communities or forums; and any integration between social media and the process lifecycle $[3,10,14,18]$.

Most BPMS already include social and collaboration features and there is a tendency that they will keep on focusing on such features [15]. Some common Social BPM features include collaborative process modeling, process recommendation, process knowledge management, social media integration (wiki, blog, forum), timeline of process execution, mobile integration, and others $[3,15,16,18,19]$.

Even though researches indicate that using social technology can improve BPM practices, the actual results of its implementation in industry are still unknown. To the best of our knowledge there is currently no information on if Social BPM features are actually being used and if they can improve traditional BPM.

\section{RESEARCH PLANNING}

\subsection{Goal}

This research aims at characterizing how Social BPM is being used in Brazilian organizations by collecting data through a survey and some interviews. Adopting the GQM paradigm [4], the research planning follows this study goal: 
XIII Brazilian Symposium on Information Systems, Lavras, Minas Gerais, June 5-8, 2017

Analyze Social BPM

With the purpose of characterizing

With respect to adoption of its practices and technologies during the BPM lifecycle

From the point of view of $\mathrm{BPM}$ participants or managers

In the context of Brazilian organizations

Following GQM, the next step is to define questions and metrics to address this defined goal. These are detailed in the next subsection.

\subsection{Questions and Metrics}

All questions and metrics used for this study are summarized in Table 1. Having characterized the organization profile and BPM practices in Question 1, in the remainder of the questions Social BPM becomes the main focus. Questions 2 to 7 characterize how organizations are using Social BPM in each BPM lifecycle phase. Question 8 aims at understanding the use of specific Social BPM software and social features. Finally, Question 9 openly asks about benefits, challenges and changes faced with Social BPM use.

Questions 3 to 7 (Table 1) and each of their metrics (14 through 23) are identical to Question 2 and its metrics, with the only difference being the BPM lifecycle phase mentioned (modeling, simulation, execution, monitoring, and improvement). Therefore, they were omitted in order to simplify this section.

All defined metrics use nominal or ordinal scales, which means that their frequencies can be counted, but they cannot be involved in more complex math calculations. For this reason, bar and pie charts were generated for each metric and conclusions were drawn according to them [21].

\section{Table 1. Questions and metrics}

\begin{tabular}{|c|c|}
\hline Question 1 & $\begin{array}{l}\text { What is the organization's current profile and its } \\
\text { BPM practices? }\end{array}$ \\
\hline Metric 1 & $\begin{array}{l}\text { Size of organization: \{micro, small, medium, } \\
\text { medium-large, large, I don't know / I'd rather not } \\
\text { answer\} }\end{array}$ \\
\hline Metric 2 & $\begin{array}{l}\text { Market sector \{private, public, non-governmental } \\
\text { organization, mixed, I don't know / I'd rather not } \\
\text { answer\} }\end{array}$ \\
\hline Metric 3 & $\begin{array}{l}\text { Industry sector: }\{\text { IT, commerce, consumer goods, } \\
\text { energy, government, logistic, chemistry and } \\
\text { biotechnology, health, financial services, } \\
\text { telecommunication, other }\end{array}$ \\
\hline Metric 4 & Federative Unit: \{All Brazilian states $\}$ \\
\hline Metric 5 & $\begin{array}{l}\text { Degree of BPM use in the organization: \{uses BPM } \\
\text { and has all its processes defined, uses BPM and } \\
\text { only has critical/important processes defined, is at } \\
\text { the beginning of BPM implementation, doesn't use } \\
\text { BPM, other\} }\end{array}$ \\
\hline Metric 6 & $\begin{array}{l}\text { BPM adoption time: }\{\text { Less than } 1 \text { year, between } 1 \\
\text { and } 3 \text { years, between } 3 \text { and } 5 \text { years, more than } 5 \\
\text { years, I don't know/I'd rather not answer\} }\end{array}$ \\
\hline Metric 7 & $\begin{array}{l}\text { BPM lifecycle phases adoption: \{design, modeling, } \\
\text { simulation, execution, monitoring, improvement, I } \\
\text { don't know/I'd rather not answer\} }\end{array}$ \\
\hline Metric 8 & $\begin{array}{l}\text { Software used for process modeling: \{Aris, Bizagi, } \\
\text { Bonita BPM, Microsoft Visio, None, Other\} }\end{array}$ \\
\hline
\end{tabular}

\begin{tabular}{|c|c|}
\hline Metric 9 & $\begin{array}{l}\text { Software used for process simulation: }\{\text { Bizagi, IBM } \\
\text { BPM, Oracle BPM, none, other\} }\end{array}$ \\
\hline Metric 10 & $\begin{array}{l}\text { Software used for process automation: \{Bizagi, } \\
\text { Bonita BPM, IBM BPM, Oracle BPM, none, other\} }\end{array}$ \\
\hline Metric 11 & $\begin{array}{l}\text { Software used for process monitoring: \{Bizagi, } \\
\text { Bonita BPM, IBM BPM, Oracle BPM, none, other\} }\end{array}$ \\
\hline Question 2 & How is Social BPM used in the Design phase? \\
\hline Metric 12 & $\begin{array}{l}\text { Presence of collaboration in Design phase: }\{\text { Yes, } \\
\text { partially, no, I don't know/Not applicable }\}\end{array}$ \\
\hline Metric 13 & $\begin{array}{l}\text { Frequency of collaboration in Design phase: }\{\text { In a } \\
\text { few processes, in some processes, in most } \\
\text { processes, in all processes, I don't know/Not } \\
\text { applicable\} }\end{array}$ \\
\hline Question 8 & How Social BPM software is being used? \\
\hline Metric 24 & $\begin{array}{l}\text { Use of Social BPM software: AAppian BPM, ARIS } \\
\text { Cloud, IBM Blueworks Live, Intalio, Oracle BPM } \\
\text { Suite, none, other }\end{array}$ \\
\hline Metric 25 & $\begin{array}{l}\text { Most used social and collaborative features in BPM } \\
\text { software: \{Content evaluation, blog, bookmarks, } \\
\text { shared calendar, categories, chat, comments in } \\
\text { model, process news feed, notifications, group } \\
\text { organization, discussion board, timeline presence, } \\
\text { tagging, mobile version, wiki, none, other }\end{array}$ \\
\hline Question 9 & How Social BPM use affects the organization? \\
\hline Metric 26 & $\begin{array}{l}\text { Challenges faced with Social BPM use: }\{\text { Open } \\
\text { answer\} }\end{array}$ \\
\hline Metric 27 & $\begin{array}{l}\text { Benefits obtained with Social BPM use: \{Open } \\
\text { answer\} }\end{array}$ \\
\hline Metric 28 & $\begin{array}{l}\text { Cultural changes that happened with Social BPM } \\
\text { use: }\{\text { Open answer }\}\end{array}$ \\
\hline
\end{tabular}

\subsection{Instruments}

The survey also included characterization questions (name of participant, name of organization, location, experience time with BPM, etc.) that were used as a means of understanding the participant's knowledge on the subject. It's noteworthy that no personal data was shared or used during analysis and that these questions were only used by the researchers for better evaluation of answers and for selecting participants for interviews.

The survey was created and shared through Google Forms. Its final format can be seen through this link https://goo.gl/WknGXW (in Portuguese). Before launching the survey, we conducted a pilot study with three independent subjects (a specialist on experimentation, a specialist on BPM, and a representative not involved in experimentation or BPM research - to represent view the responding subjects). The goal of this pilot study was to validate the questionnaire mitigating potential threats to validity (e.g., identifying possible difficulties in understanding users could have) and correcting eventual mistakes.

The survey was available for answers from September 27 to October 28 in 2016. The survey population consists of organizations that use BPM. The answers to Question 1 could be used to assure that respondents were representatives of the study population. We tried to make the sample as large and unbiased as possible to avoid threats concerning the sampling strategy. Due to cost and time constraints, convenience sampling was adopted and the sample consisted of our acquaintances and whoever was 
reached through social media publications. Personal e-mails were sent and the participants were asked to share the survey with their acquaintances. Considering this, the survey was sent to $268 \mathrm{BPM}$ professionals by e-mail and was also shared in Facebook, LinkedIn and Google+ groups.

\section{RESEARCH OUTCOMES}

\subsection{Survey Results}

In total, 31 answers were received. Among those answers, 3 were discarded for having data on the same organization, which means that only 1 answer per organization was considered. Another answer was discarded since it belonged to a self-employed subject. Thus, the number of answers available for analysis was reduced to 27 .

In this research, regarding Question 1, 48\% of answers came from large organizations (Fig. 1). In addition, $4 \%$ came from mediumsized organizations, $11 \%$ from small organizations and $18 \%$ from microbusinesses.

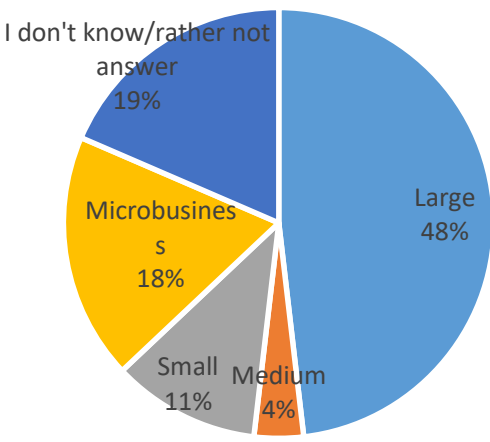

Fig. 1. Organization size graph

It's noteworthy that most survey answers (59.25\%) came from organizations located in Rio de Janeiro area, as seen in Fig. 2, where the authors are based. However, the set also included answers $(40.75 \%)$ from states in the Southeast and Northeast of Brazil.

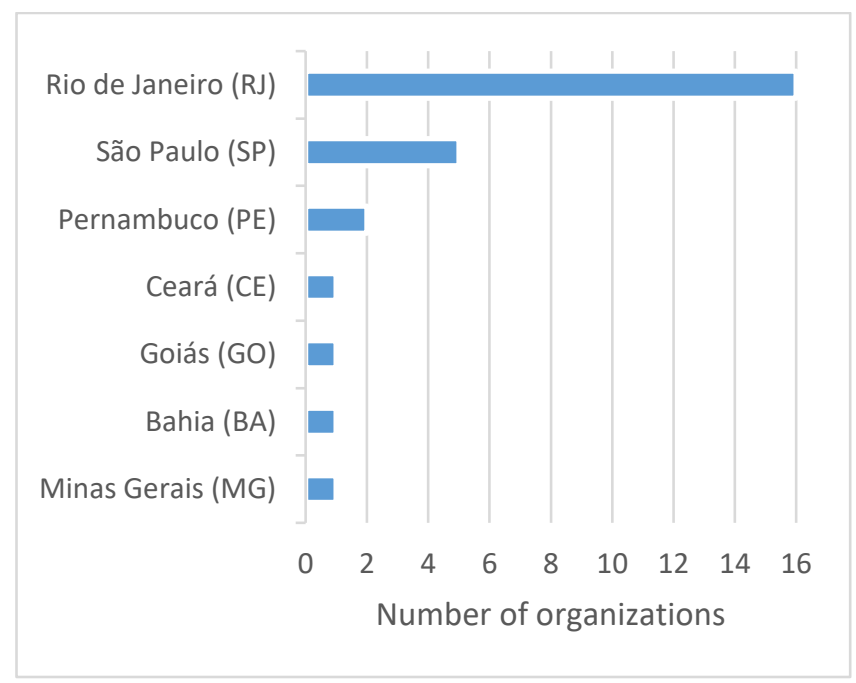

Fig. 2. Location of organizations by state graph

As can be seen in Fig. 3, most organizations operate in the IT business and some in the education sector. There were also some answers from other sectors such as commerce, consulting, and financial services.

Concerning the adopted BPM phases, Fig. 4 shows that the most adopted phase is Modeling (66.6\%), followed by Design and Improvement $(55.5 \%$ each). On the other hand, process Simulation is the least adopted $(14.8 \%)$, followed by process Monitoring (33.3\%). Indeed, the latter two phases require more powerful software and skilled employees to be performed correctly.

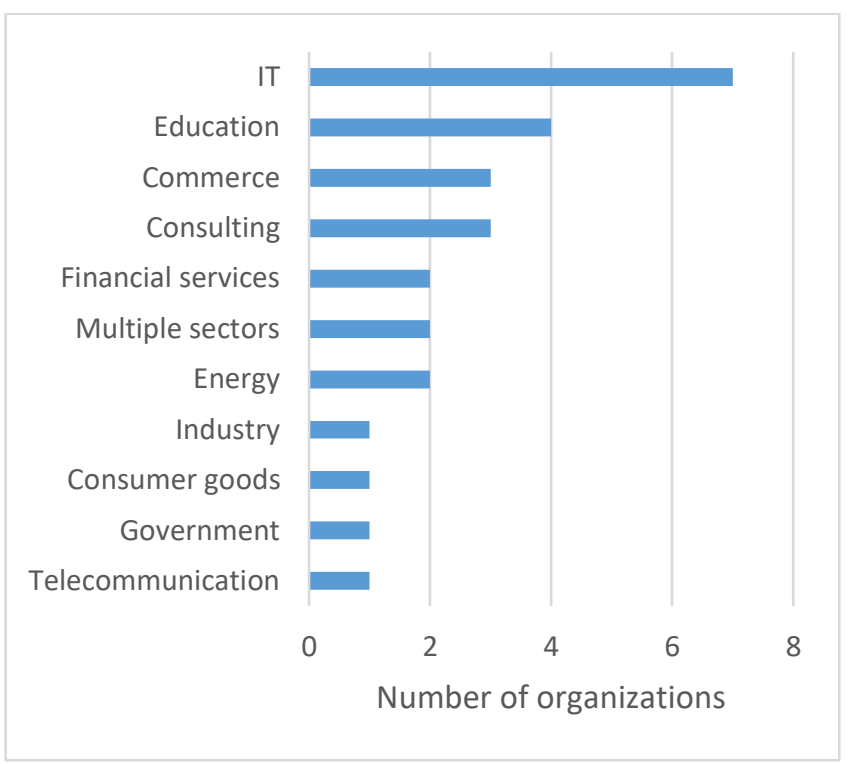

Fig. 3. Industry sector graph

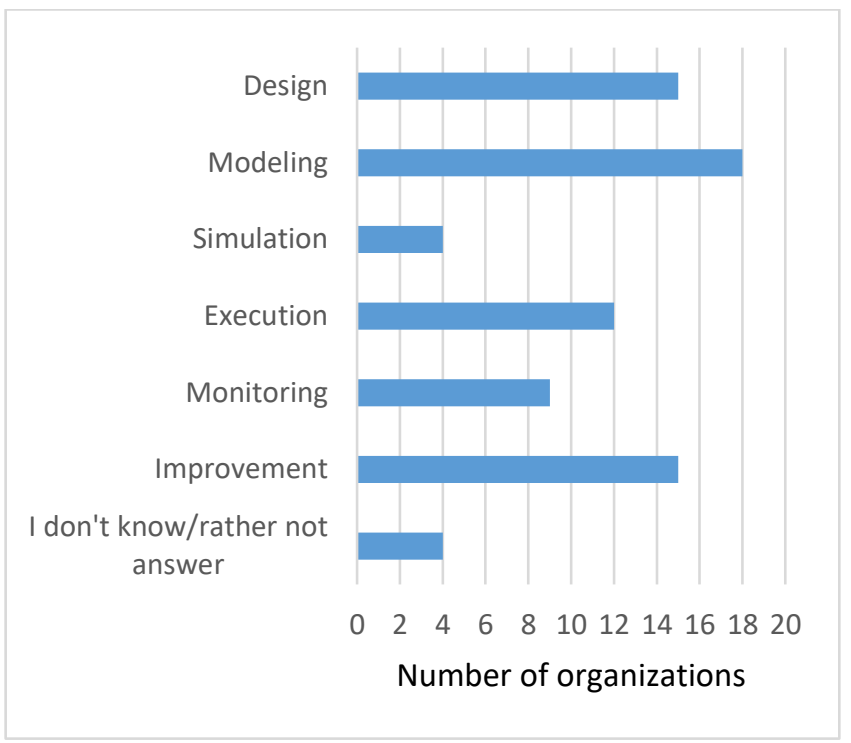

Fig. 4. BPM lifecycle phases adoption graph

Fig. 5 shows the data concerning collaboration in each of BPM phases. During this analysis, the original set was reduced from 27 to 22 , because 5 organizations claimed that BPM is not performed internally. During this section of the survey, the subjects were given the option to give more detailed information on how collaboration happens in each phase. All relevant data was included in this analysis. 


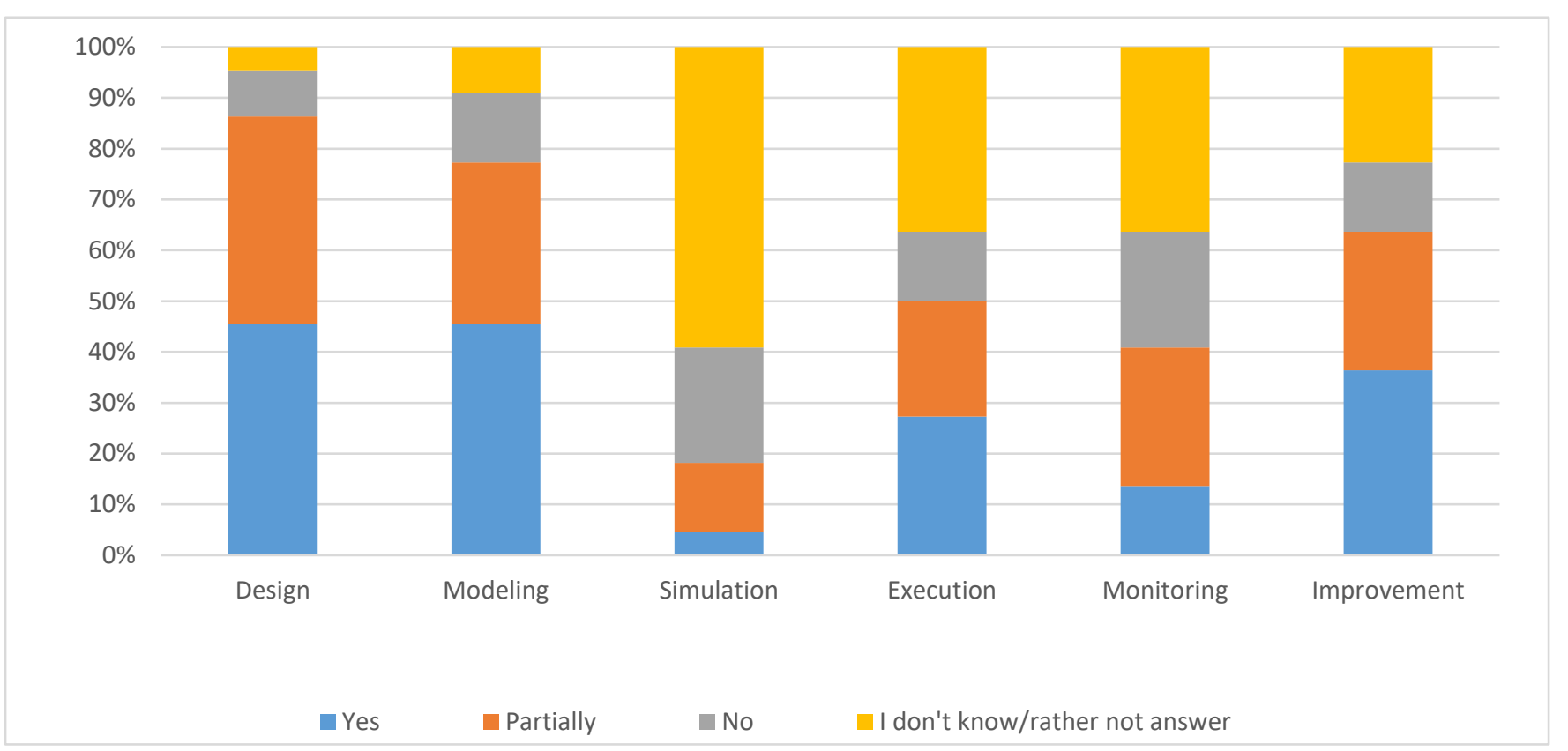

Fig. 5. Collaboration in each BPM phase graph

Regarding the Design phase (Fig. 5) and Question 2, 45\% of organizations claim that this phase happens collaboratively and $41 \%$ claim that collaboration happens partially. On the other hand, $9 \%$ informed that this phase does not have collaboration. In the data collected by the survey, $18 \%$ of employees informed that collaboration happens in all business processes and also $18 \%$ informed that it happens in a few processes.

According to this survey, Design is the most collaborative BPM phase, with $86 \%$ of the organization representatives claiming it happens completely or partially collaborative. This is probably due to its direct impact on stakeholders and of it being the first step taken before the organizations performs any other BPM activity.

As also seen in Fig. 5 and regarding Question 3, 45\% of organizations claimed that the Modeling phase happens collaboratively and $32 \%$ affirmed that collaboration happens partially, while $14 \%$ said that collaboration does not happen. Most organizations claimed using Bizagi as their main process modeling software, but Microsoft Visio and Aris were also reported as being largely used.

A representative of a financial services organization that does not perform collaborative modeling stated that "modeling is performed by the IT team without involvement of the operational team, which is affected by changes". On the other hand, a representative of a large organization with collaborative modeling claims that "teams are built for modeling each process so that nobody in particular is seen as responsible for the process". A representative of a consulting microbusiness affirms that "processes and business rules are discussed and defined in meetings in a way that all participants are in agreement".

In Fig. 5 and with reference to Question 4, it is also possible to observe that only $4 \%$ of organizations claim performing process Simulation collaboratively, while $14 \%$ claim it happens partially, and $23 \%$ claim that it does not happens collaboratively at all. Simulation phase is the less collaborative phase and, in addition, there is almost no information on how Social BPM can be achieved in this phase.

With respect to Question 5, collaborative process Execution (Fig. 5) happens for $27 \%$ of the organizations, while $23 \%$ claim that it happens partially, and $14 \%$ claim that it does not happen collaboratively. Most organizations claimed that they do not use software for process automation and execution, but, among the ones that do, Bizagi and Orquestra BPM are the most mentioned. Also, one organization cited the high cost of software as a disadvantage.

Regarding Question 6, Fig. 5 also shows that, among the surveyed organizations, $14 \%$ claim that process Monitoring happens collaboratively and $27 \%$ claim that collaboration happens partially, while $23 \%$ affirmed that collaboration does not happen in this phase. Similar to the Execution phase, most organizations claim that they do not use software for process monitoring. However, some organizations claimed that they use their own software and some use Bizagi for this purpose.

Finally, regarding Question 7, the Improvement phase happens collaboratively in $36 \%$ of organizations, while collaboration happens partially in $27 \%$ of them (Fig. 5). However, $14 \%$ of them claim that this phase does not happen collaboratively.

Summing up, the most adopted phases with collaboration (Fig. 5) are Design (with $86 \%$ of organizations claiming that collaboration happens totally or partially), Modeling (77\%), and Improvement $(63 \%)$. On the other hand, the less collaborative phases are Simulation (18\%), Monitoring (41\%), and Execution (50\%).

With respect to Question 8 and as seen in Fig. 6, when asked about most used social and collaborative features in BPM software, 5 organizations claimed using timeline feature, probably for process execution and monitoring. Content evaluation, shared calendar, notifications, group organization, and mobile versioning were informed as being used by 4 organizations each. 3 organizations claimed using online chat, model comments, discussion panel and tagging each. 
Most current BPM software have collaborative features, but that is not their main objective. Some of them claim to be Social BPM software, which are the ones that were considered on this research. However, when asked about the use of a Social BPM software, most companies (17 participants) claimed to not be using any of the options. On the other hand, one organization uses IBM Blueworks and another one adopts Fluig.

Organizations were also asked to openly discuss about benefits, challenges, and cultural changes faced by using Social BPM, as referenced by Question 10. During analysis, these qualitative text answers were aggregated and summarized in order to provide a simpler overview.

When asked about the challenges of adopting Social BPM, 6 organizations mentioned a resistance to changes by employees or that there is need for cultural changes. 3 organizations said that the software is hard to use or that the users have little knowledge on them. Moreover, 2 organizations mentioned the high cost of deploying a more powerful system.

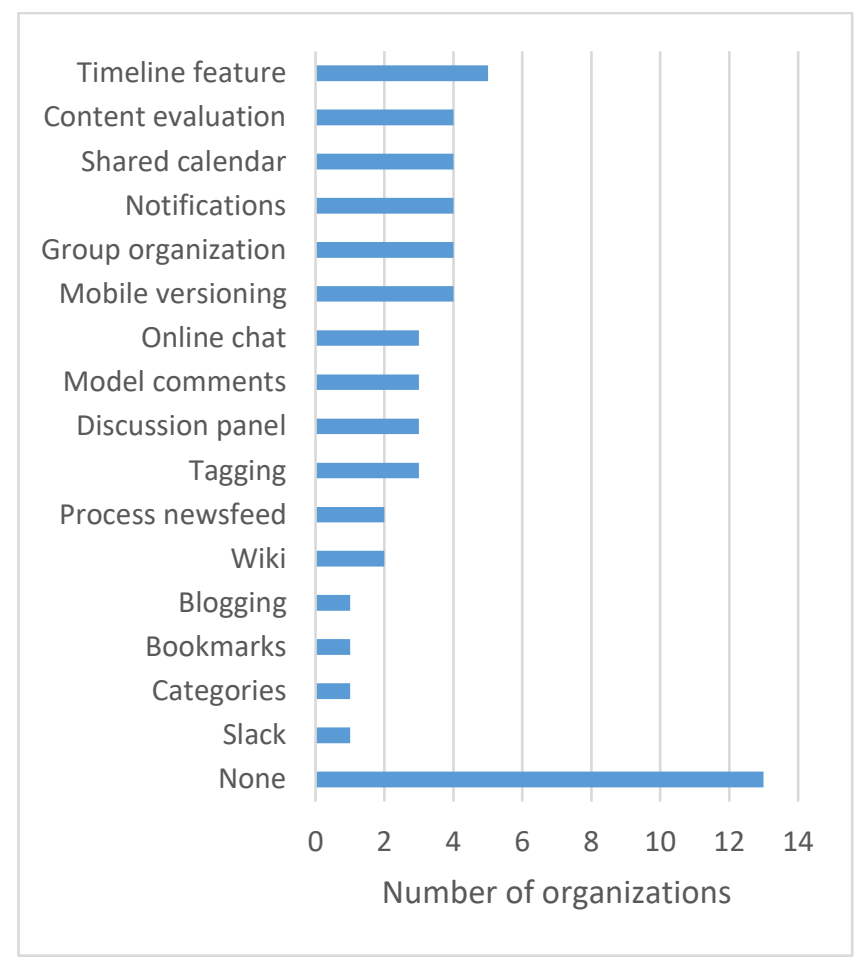

Fig. 6. Use of social and collaborative features

Regarding the benefits of Social BPM, subjects mentioned the following: centralized repository, process integration, BPM communities for improving processes, knowledge management, work optimization, improvement of communication, easiness of sharing and creating artifacts, faster decision making, and less operational expenses.

When asked about cultural changes, 6 organizations claimed that changes happened, but did not specify any in particular. One subject affirmed that "by just adopting collaborative tools, an increase of collaboration levels and of knowledge among people could be seen". Another subject claimed that users are still getting used with collaborating. One other subject answered that the idea of collaborating in order to improve and optimize the work environment has increased and that all participants are given the opportunity to collaborate.

\subsection{Interviews}

After the initial analysis, three subjects were invited for an interview in order to explain with more details how Social BPM was happening in their organizations and therefore improve the qualitative analysis of the results.

Since almost half of the answers came from large organizations, two of them were chosen based on the most popular industry sectors of the respondents (IT and education). The other organization is representing microbusinesses, which also represent a big part $(18 \%)$ of received answers. Interviewees were chosen based on the completeness of their original survey answers and on their availability and willingness to participate in the research.

After choosing the participants, an interview script was made for each, consisting of a generalized set of questions to improve the quality of their survey answers. The initial outline of these questions (adapted during the interviews based on the specific answers) was:

- Who is involved in the $<$ BPM phase $>$ team?

- $\quad$ Since when $<$ BPM phase $>$ happens collaboratively?

- Is collaboration encouraged in the work environment? How does that happen?

- Since when collaborative functions in BPM software have been used? And how are they used?

However, during the interviews, new questions would spontaneously come up, which allowed for a better conversation flow and better information. The interviewer allows the interviewee to speak as freely as possible. All interviews happened in November 2016 through Skype videoconference and lasted approximately one hour each. They were recorded with a voice recorder and transliterated for analysis and interpretation.

The first interviewee works at a large IT company, that adopts all BPM phases (except for simulation) and that has defined all its business processes. He claims that Design, Modeling and Improvement phases always happen in team meetings of 3 people. A model is built using Microsoft Visio ${ }^{1}$ and then it is shared through Fluig ${ }^{2}$, which is a web based tool for process execution and monitoring. Also, the organization has a research sector and one of the topics under interest is Social BPM.

The organization management imposed the use of Fluig as its main platform and encourages employees to share and collaborate through it. Fluig is similar to a social network that allows content sharing and has timeline, notification, and groups features, which are integrated with internal business processes, allowing for more efficient BPM execution and monitoring. Also, these communities can be internal or external (with customers) and each one can be used for different topics, such as organizational announcements, Fluig assistance or business processes and BPMN discussion.

The second interviewee works at a large education organization that is at the beginning of BPM implementation. It adopts the Design, Modeling, and Improvement phases. Each area has a team of three people and they are involved in creating and validating the process model. They use Bizagi ${ }^{3}$ and Blueworks Live ${ }^{4}$ for creating the model and then it is shared with stakeholders through

\footnotetext{
${ }^{1}$ Microsoft Visio - https://products.office.com/ptbr/visio/flowchart-software

${ }^{2}$ Fluig - https://www.fluig.com/

${ }^{3}$ Bizagi - http://www.bizagi.com/

${ }^{4}$ Blueworks Live - https://www.blueworkslive.com/
} 
Sharepoint ${ }^{5}$. The use of Sharepoint enhances transparency, since it contains text descriptions for each activity and any other important information is available for the user.

This subject also claims that having team meetings for modeling processes is a recent change in the organization, mainly because the employees do not have collaborative vision. Even though there is a growing concern for collaboration to happen in the company, the members have not had the need of using other social features in BPMS and are focusing on improving the current practices.

The third interviewee is the director of a consulting microbusiness, that is at the beginning of BPM implementation and that adopts the Design and Modeling phases internally. Design and modeling happens with a three-person team meeting, in which two are business partners and the other one is involved with finances. Previously, one person was responsible for developing artifacts and models, but this was changed due to communication issues. Nowadays, the meetings happen through Google Talk and screen sharing is used so that one can perform team aware changes on the model on Aris or Bizagi while the discussion is happening.

Since the company is small, they do not have plans for adopting other phases or even adopting other BPMS because it is expensive and hard to deploy in the organization.

\subsection{Discussion}

BPM happens in Brazilian organizations and these organizations are concerned in performing collaborative tasks to improve their results. According to the data, Design, Modeling, and Improvement phases are the phases that more frequently happen in a collaborative manner. On the other hand, Simulation, Execution, and Monitoring phases happen with little or no collaboration. Also, as observed during the interviews, apparently, collaboration occurs mainly in meetings (face-to-face or online) with small teams.

Collaborative features of BPM software are still underexplored, since most users do not know about them or have not felt the need to use them. However, it does not prevent collaboration from happening among workers. And it is possible to see the growing tendency of collaborative work being integrated in BPM lifecycle phases.

Some organizations are already investing in Social BPM technology and are encouraging collaboration through BPM tools, as said by the first interviewee. The Fluig platform mentioned by him is used by some large companies for executing and automating their processes. However, high costs of more robust software (such as the Fluig platform) can be an impediment for smaller organizations. That's probably why smaller organizations focus on the Design and Modeling phases (which can be done with inexpensive tools) and do not foresee expansion to other lifecycle phases in the near future, unlike the third interviewee's organization that has plans for expanding social collaboration throughout other BPM phases.

Based on the results, it is noticeable that people started to understand the benefits of collaborative work for themselves and for the organization, such as improvement of artifacts and better sharing of information. The greatest issue is encouraging collaboration and making it happen whenever possible and applicable, because it requires changes in the work environment,

\footnotetext{
${ }^{5}$ Microsoft Sharepoint - https://products.office.com/enus/sharepoint/collaboration
}

in used tools, and in people's culture. Also, in some situations collaborative tasks can be more expensive and time-consuming, so it needs to be planned carefully by the organization.

The results provide indication that Social BPM is being used in some Brazilian organizations, mostly without the direct aid of collaborative features. The most common case is team organization for performing Design and Modeling phases in meetings. In addition to that, the idea of encouraging collaboration or using collaborative software is usually imposed by organization's own management or by incentive of an employee that understands the benefits of collaborative work.

Concluding form what most organizations described, collaboration should be planned and start with face-to-face meeting with a diverse team, where all can participate, provide opinions, and contribute in building artifacts. Organizations should change the idea that each person is responsible for a specific knowledge and focus on better knowledge management. It is worth mentioning that collaboration in BPM must be previously planned, because not all processes would necessarily be benefited with collaborative work [13].

\subsection{Threats to Validity}

This section discusses the main limitations of this survey, including the threats to validity, classified according to [21].

One initial threat to internal validity could be poor instrumentation, which could affect subjects' understanding of concepts and questions. For this reason, a pilot study was performed with 3 people, so any problem could be identified and corrected before the survey was opened for answers. Social BPM may still be a broad term and can have multiple interpretations, and this could affect the understanding of the questions. However, in order to reduce any misunderstanding, at the beginning of the survey, all concepts were briefly explained.

Concerning construct validity, we strictly followed the GQM paradigm for planning the survey and handled nominal and ordinal scale metrics as recommended by literature. Also, the main decisions taken were based on literature (e.g., mapping Social BPM practices against well-defined BPM lifecycle phases) and open text questions were included to allow triangulating the results.

Additionally, we conducted interviews for obtaining a better understanding on the practices being used. The answers were analyzed qualitatively, but no formal technique (such as grounded theory) was used [12]. A larger number of interviews could improve this research's quality; however, even a single interview can bring new observations to the field.

As previously said, the samples were as large and as unbiased as possible to avoid threats concerning the sampling strategy, but, due to limited cost and time, the sample was not as random as it could ideally be. Even though it consisted mostly of personal contacts and acquaintances and since we cannot afford the effect of convenience sample, the results are still noteworthy that all participants in fact operate on Brazilian companies.

The greatest limitation of this research, concerns the sample size and representativeness. The sample had 27 valid answers among surveyed organizations and a large concentration in Brazil's southeast region, which affects both conclusion and external validity. Even though it represented approximately $10 \%$ of the contacted representatives, in this scenario, the results cannot be generalized to a nationwide scale. Therefore, we ask for replications (in national and international contexts). 
It is noteworthy, however, that this is the first survey on the practical use of Social BPM and that we still consider the initial indications valuable, especially when including the additional qualitative results obtained from the interviews.

\section{CONCLUDING REMARKS}

The goal of this paper was to identify and characterize Social BPM use in Brazilian organizations regarding its adoption and the practices used throughout the BPM lifecycle. The results indicate that most of the investigated organizations perform some BPM phases collaboratively, mainly Design, Modeling, and Improvement phases. Simulation, Execution, and Monitoring phases generally do not happen collaboratively. Survey and interview results also indicate that, even though BPM software has social features, these are still not widely used and mainly unknown by users. The results also indicate that organizations and employees already understand the benefits of collaborative work, but that there is a long path until it happens efficiently.

Organizations interested in integrating collaborative BPM practices in their daily routine can benefit from this study. They can understand how collaboration is happening in other places and develop ways to improve and adapt how collaboration is currently happening in their own environment.

These results can be also used by other researchers in order to develop studies on the same field or to develop solutions on the addressed issues. Also, the structure and methodology of this study can be adapted and reused to be executed in another context. This can help to improve conclusion validity of the current results or even allow drawing new conclusions on the topic.

As future work, besides carrying out a new execution of the survey in different contexts, researchers can identify better ways to encourage collaboration to happen in the workplace, or even propose solutions that allow collaboration through software. Also, a study comparing social and collaborative features of popular BPMS would be helpful for understanding the benefits of one tool against the other. Empirical evidence of the actual benefits and disadvantages of collaborative BPM tasks compared with traditional BPM tasks are also lacking.

\section{ACKNOWLEDGMENTS}

This work is partially funded by FAPERJ (APQ1- 210.518/2016) and by CNPq (project \#460627/2014-7). We would also like to thank all the survey participants and in particular the three subjects which allowed us to conduct in-depth interviews to refine our results.

\section{REFERENCES}

[1] ABPMP Brasil 2013. BPM CBOK V3.0: Guia para o Gerenciamento de Processos de Negócio. Corpo Comum de Conhecimento. (in Portuguese)

[2] ABPMP Brasil 2015. Pesquisa Nacional em Gerenciamento de Processos de Negócio da ABMP Brasil. Revista BPM Global Trends (in Portuguese).

[3] Araujo, R.M. de and Magdaleno, A.M. 2015. Social BPM: Processos de Negócio, Colaboração e Tecnologia Social. Minicursos SBSI (Goiânia, GO, Brasil, 2015), 32-36 (in Portuguese).

[4] Basili, V.R. and Rombach, H.D. 1994. Goal question metric paradigm. Encyclopedia of Software Engineering. 1, (1994), 528-532.
[5] Davis, J.G. and Greif, I. 1991. Computer-Supported Cooperative Work: A Book of Readings. JSTOR.

[6] Dean, D.L. et al. 2006. Making the Collaboration Engineering Investment Decision. (2006), 16a-16a.

[7] De Vreede, G.-J. and Briggs, R.O. 2005. Collaboration engineering: designing repeatable processes for high-value collaborative tasks. Proceedings of the 38th Annual Hawaii International Conference on System Sciences (2005), 17c$17 \mathrm{c}$.

[8] Dumas, M. et al. 2013. Fundamentals of Business Process Management. Springer.

[9] Ellis, C.A. et al. 1991. Groupware: some issues and experiences. Communications of the ACM. 34, 1 (1991), 39-58.

[10] Erol, S. et al. 2010. Combining BPM and social software: contradiction or chance? Journal of Software Maintenance and Evolution: Research and Practice. 22, 6-7 (2010), 449-476.

[11] Fuks, H. and Pimentel, M. 2011. Sistemas Colaborativos. Elsevier (in Portuguese).

[12] Glaser, B.G. and Strauss, A.L. 2009. The discovery of grounded theory: Strategies for qualitative research. Transaction publishers.

[13] Hansen, M.T. 2009. When internal collaboration is bad for your company. Harvard business review. 87, 4 (2009), 8288.

[14] Magdaleno, A.M. et al. 2011. A Roadmap to the Collaboration Maturity Model (CollabMM) Evolution. (Lausanne, Switzerland, 2011), 105-112.

[15] Magic Quadrant for Intelligent Business Process Management Suites: 2016. https://www.gartner.com/doc/reprints?id $=1$ $3 F 6 M 73 T \& c t=160819 \& s t=s b \&$ cldee $=b W F 0 a G V 1 c z E 2 M$ DlAZ21haWwuY29t. Accessed: 2016-09-08.

[16] Mathiesen, P. et al. 2012. Applying Social Technology to Business Process Lifecycle Management. Business Process Management Workshops. F. Daniel et al., eds. Springer Berlin Heidelberg. 231-241.

[17] Pflanzl, N. and Vossen, G. 2014. Challenges of Social Business Process Management. 2014 47th Hawaii International Conference on System Sciences (Los Alamitos, CA, USA, 2014), 3868-3877.

[18] Schmidt, R. and Nurcan, S. 2008. BPM and Social Software. Business Process Management Workshops. D. Ardagna et al., eds. Springer Berlin Heidelberg. 649-658.

[19] Swenson, K.D. et al. 2011. Social BPM: Work, Planning and Collaboration Under the Impact of Social Technology. CreateSpace Independent Publishing Platform.

[20] Tapscott, D. 2012. Four principles for the open world,

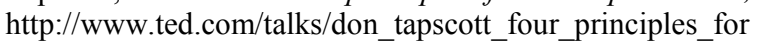
_the_open_world_1.

[21] Wohlin, C. et al. 1999. Experimentation In Software Engineering: An Introduction. Springer Berlin Heidelberg. 